\title{
Duodenal and nodal follicular lymphomas are distinct: the former lacks activation-induced cytidine deaminase and follicular dendritic cells despite ongoing somatic hypermutations
}

\author{
Katsuyoshi Takata ${ }^{1}$, Yasuharu Sato ${ }^{1}$, Naoya Nakamura ${ }^{2}$, Yara Yukie Kikuti ${ }^{2}$, \\ Koichi Ichimura ${ }^{1}$, Takehiro Tanaka ${ }^{1}$, Toshiaki Morito ${ }^{1}$, Maiko Tamura ${ }^{1}$, Takashi Oka ${ }^{1}$, \\ Eisaku Kondo ${ }^{1}$, Hiroyuki Okada ${ }^{3}$, Akira Tari ${ }^{4}$ and Tadashi Yoshino ${ }^{1}$ \\ ${ }^{1}$ Department of Pathology, Okayama University Graduate School of Medicine Dentistry and Pharmaceutical \\ Sciences, Okayama, Japan; ${ }^{2}$ Department of Pathology, Tokai University School of Medicine, Isehara, \\ Kanagawa, Japan; ${ }^{3}$ Department of Gastroenterology and Hepatology, Okayama University Graduate School of \\ Medicine Dentistry and Pharmaceutical Sciences, Okayama, Japan and ${ }^{4}$ Department of Internal Medicine, \\ Hiroshima Red Cross Hospital and Atomic-Bomb Survivors Hospital, Hiroshima, Japan
}

\begin{abstract}
Although most follicular lymphomas are believed to be of nodal origin, they sometimes originate from the duodenum. We have reported that the latter differ from nodal follicular lymphomas in having lower clinical stages and uniformly low histological grades, along with variable region of immunoglobulin heavy chain gene (VH) usage that is more similar to mucosa-associated lymphoid tissue (MALT) lymphomas. Little is known, however, about whether they possess other characteristics of nodal follicular lymphomas, particularly ongoing mutations with follicular dendritic cells. We examined 17 cases for which PCR identified the monoclonal bands of the immunoglobulin gene. The duodenal cases showed ongoing mutations, but they lacked activationinduced cytidine deaminase (AID) expression, a statistically significant difference from the nodal cases $(P<0.001)$, and their follicular dendritic cell networks were disrupted. Moreover, not only were $V H$ deviations observed but also they used very restricted VH genes. Although the mechanisms of ongoing mutation without AID and follicular dendritic cell were not clarified, restricted $\mathrm{VH}$ usage strongly suggested that antigen stimulation was involved, and that was similar to MALT Iymphomas. In conclusion, duodenal follicular lymphomas were shown to be unique, in that they had ongoing hypermutations such as nodal cases, but the mechanisms involved in the hypermutation were quite different; furthermore, restricted $\mathrm{VH}$ usage suggested a strong similarity to the antigen-dependent origin of MALT Iymphomas.
\end{abstract} Modern Pathology (2009) 22, 940-949; doi:10.1038/modpathol.2009.51; published online 24 April 2009

Keywords: duodenal follicular lymphoma; AID; follicular dendritic cell

We have reported that duodenal follicular lymphomas are frequently found in the second portion of the duodenum. ${ }^{1}$ Although they express CD10 and bcl-2 and harbor $t(14 ; 18)$ translocation similar to nodal follicular lymphomas, ${ }^{2}$ most of them are obviously at lower clinical stages than the nodal cases (most are stage I-II) and have lower histolo-

Correspondence: Professor T Yoshino, MD, PhD, Department of Pathology, Okayama University Graduate School of Medicine, Dentistry and Pharmaceutical Sciences, 2-5-1 Shikata-cho, Okayama city, Okayama, 700-8558, Japan.

E-mail: yoshino@md.okayama-u.ac.jp

Received 25 January 2009; revised 24 February 2009; accepted 25 February 2009; published online 24 April 2009 gical grading with rather dominantly uniform intermediate small cleaved cells.

The vast majority of follicular lymphomas originate from lymph nodes, and earlier reports have clearly indicated that these follicular lymphoma cells derive from germinal-center B cells: both cells share characteristics such as accumulation of somatic hypermutation and ongoing mutations. ${ }^{3}$ Furthermore, they interact with follicular dendritic cells. In an earlier report, we also described that duodenal follicular lymphomas have a high frequency of $\mathrm{IgVH} 4$ gene usage as in mucosa-associated lymphoid tissue (MALT) lymphomas, with which they share other characteristics. ${ }^{4-6}$ Localized disease is one of main characteristics of MALT lymphomas. 
From these findings, we considered whether duodenal follicular lymphomas have other differences from nodal follicular lymphomas, and decided to examine their expression of activationinduced cytidine deaminase (AID), which plays the important roles of class-switch recombination and somatic hypermutation, ${ }^{7}$ and the patterning of their follicular dendritic cell networks. It is reported that AID expression is associated with ongoing mutation in nodal follicular lymphoma, ${ }^{8}$ but is not correlated with diffuse large B-cell lymphomas. ${ }^{9}$ Although other characteristics of duodenal follicular lymphomas have been described, to the best of our knowledge no report has focused on their somatic and ongoing mutations, which are the most important similarity to germinal-center B-cell lymphomas.

In this report, we discovered that duodenal follicular lymphomas showed ongoing somatic hypermutations similar to nodal cases; unlike the latter, however, they lack AID and have disrupted follicular dendritic cell networks.

\section{Materials and methods}

\section{Patient Selection}

Buffered formalin-fixed and paraffin-embedded tissues $(10 \%)$ were used for histological, immunohistochemical and immunogenotypical studies. We chose 30 consecutive patients of duodenal follicular lymphoma, successfully amplified the monoclonal rearranged band of the $V H$ gene in 17 of these patient samples, and focused on these samples for further analyses. Informed consent for examination was obtained for the use of all samples.

\section{Immunohistochemistry}

Formalin-fixed, paraffin-embedded tissue sections were subjected to immunohistochemical staining. Staining was carried out using heat-induced epitope retrieval or trypsin-induced retrieval, an avidinbiotin complex method, and an automated immunostainer (Ventana Medical System, Tuscon, AZ, USA), as described earlier. ${ }^{10}$ The antibody panel used to assess these cases was as follows (clone, dilutions): CD20 (L26, 1:200), CD3 (PS-1, 1:50), CD10 (56C6, 1:50), CD5(4C7, 1:100), bcl-2 (3.1, 1:200), CD23 (1B12, 1:100) and Ki-67 (MIB-1, 1:5000) (Novocastra, Newcastle-upon-Tyne, UK); CD21 (1F8, 1:20), MUM1 (MUM1p, 1:50) (DAKO Cytomation, Glostrup, Denmark A/S); bcl-6 (D-8, 1:100) (Santa Cruz, CA, USA); and cyclin D1 (SP4, ready to use) (Nichirei, Tokyo, Japan); AID (ZA001, 1:100) (ZYMED, South San Francisco, CA, USA). As for CD20, CD3, CD10, CD5, cyclin D1, bcl-2, bcl-6 and MUM-1 antigens, positivity was determined when $30 \%$ or more lymphoma cells were positive for their antibodies. For AID expression in tumor follicles, samples with $20 \%$ or more expressing cells were evaluated as positive. Ki-67-positive cells were counted in tumor follicles.

\section{DNA Extraction and PCR}

DNA was extracted from paraffin-embedded tissue using the QIAamp DNA Micro Kit- (Qiagen Inc., Valencia, CA, USA). The variable region (CDR2 and FW3) and VDJ region (CDR3) of the immunoglobulin heavy-chain gene were amplified by semi-nested PCR, using the primers of FR2, $L J H$ and $V L J H$ as described earlier. ${ }^{11,12}$ Primers were as follows: $5^{\prime}$-CC GGRAARRGTCTGGAGTGG-3' ${ }^{\prime}$, as upstream consensus $V$ region primer (FR2); 5'-CTTACCTGAGGA GACGGTGACC- $3^{\prime}$, as a consensus $J$ region primer $(L J H) ; \quad 5^{\prime}$-GTGACCAGGGTNCCTTGGCCCC- ${ }^{\prime}$, as a consensus $J$ region primer $(V L J H)$. PCR products were purified using the QIAquick PCR purification kit (Qiagen). Then $1 \mu \mathrm{l}$ of the PCR product was applied for direct sequencing (ABI PRISM Model 3100, version 3.7, Applied Biosystems).

\section{Ongoing Mutation Study and Analysis}

PCR products were ligated into the pDrive cloning vector and transformed into DH5alpha cells (TaKaRa Bio. Inc., Tokyo, Japan) according to the instruction manual (PCR cloning kit, Qiagen). After an overnight culture, 10 and more white colonies were picked from a Luria-Bertani (LB) agar plate based on the X-Gal screening, then placed into $25 \mu \mathrm{l}$ of the Insert Check ready kit solution (TOYOBO, Osaka, Japan). PCR conditions consisted of 30 cycles of $94{ }^{\circ} \mathrm{C}$ for $30 \mathrm{~s}, 60^{\circ} \mathrm{C}$ for $5 \mathrm{~s}$ and $72{ }^{\circ} \mathrm{C}$ for $30 \mathrm{~s}$. Ten samples including correct PCR products confirmed by checking $2 \%$ gel electrophoresis for each case were sequenced by the same method as described above. Then, the closest germline was searched for by BLAST using the immunoglobulin sequence (NCBI). Ongoing mutation was determined by dividing the cumulative number of partially shared mutations (mutations shared by some clones but not by all the $V H$ gene clones) and unique mutations (mutations unique to a distinct $\mathrm{VH}$ gene clone) with the expected number of mutations calculated based on the PCR error rate $\left(4.5 \times 10^{-4}\right.$ change per base per PCR cycle) by the method described above. ${ }^{7}$ The $\chi^{2}$ test with Yates' correction when appropriate was used to evaluate the association of qualitative variables in the different groups. Statistical analysis was carried out using Statcel2 for Windows. Values of $P<0.05$ were considered statistically significant.

\section{Fluorescence In Situ Hybridization}

Fluorescence in situ hybridization (FISH) for $\mathrm{t}(14 ; 18)(\mathrm{q} 32 ; \mathrm{q} 21) / I G H-B C L 2$ translocations were 
carried out using the BCL2 FISH DNA split signal probe (DAKO Cytomation, Glostrup, Denmark A/S) according to the manufacturer's instructions. We examined FISH directly on paraffin-embedded tissue sections and detected split signal of BCL2 gene as descried earlier. ${ }^{13}$

Table 1 Clinicopathologic features of duodenal follicular lymphoma

\begin{tabular}{lccccccccccc}
\hline Patient no. & Age/sex & Stage & Grade & CD5 & CyclinD1 & CD10 & bcl-2 & bcl-6 & MUM-1 & $t(14 ; 18)$ & CD21 pattern \\
\hline 1 & 75/M & I & 1 & - & - & + & + & + & - & Not tested & Duodenal \\
2 & 57/M & I & 1 & - & - & + & + & + & - & Not tested & Duodenal \\
3 & 58/M & IV & 1 & - & - & + & + & + & - & + & Duodenal \\
4 & 75/M & II2 & 1 & - & - & + & + & + & - & - & Duodenal \\
5 & 71/F & I & 1 & - & - & + & + & + & - & + & Duodenal \\
6 & 66/F & I & 1 & - & - & + & + & + & - & - & Nodal \\
7 & 51/M & I & 1 & - & - & + & + & + & - & + & Duodenal \\
8 & 49/M & II2 & 1 & - & - & + & + & + & - & + & Duodenal \\
9 & 62/F & II2 & 1 & - & - & + & + & + & - & + & Duodenal \\
10 & 54/M & I & 1 & - & - & + & + & + & - & + & Duodenal \\
11 & IV & IV & 1 & - & - & + & + & + & - & + & Duodenal \\
12 & 53/F & II2 & 1 & - & - & + & + & + & - & + & Duodenal \\
13 & 57/F & I & 2 & - & - & + & + & + & - & + & Duodenal \\
14 & 56/M & II2 & 1 & - & - & + & + & + & - & + & Duodenal \\
15 & 66/F & II2 & 1 & - & - & + & + & + & - & + & Duodenal \\
16 & 55/F & II2 & 1 & - & - & + & + & + & - & + & Nodal \\
17 & 63/F & II2 & 1 & - & - & + & + & + & - & + & Duodenal \\
\hline
\end{tabular}

F, female; M, male.

Immunophenotypic data were analyzed using immunohistochemistry.
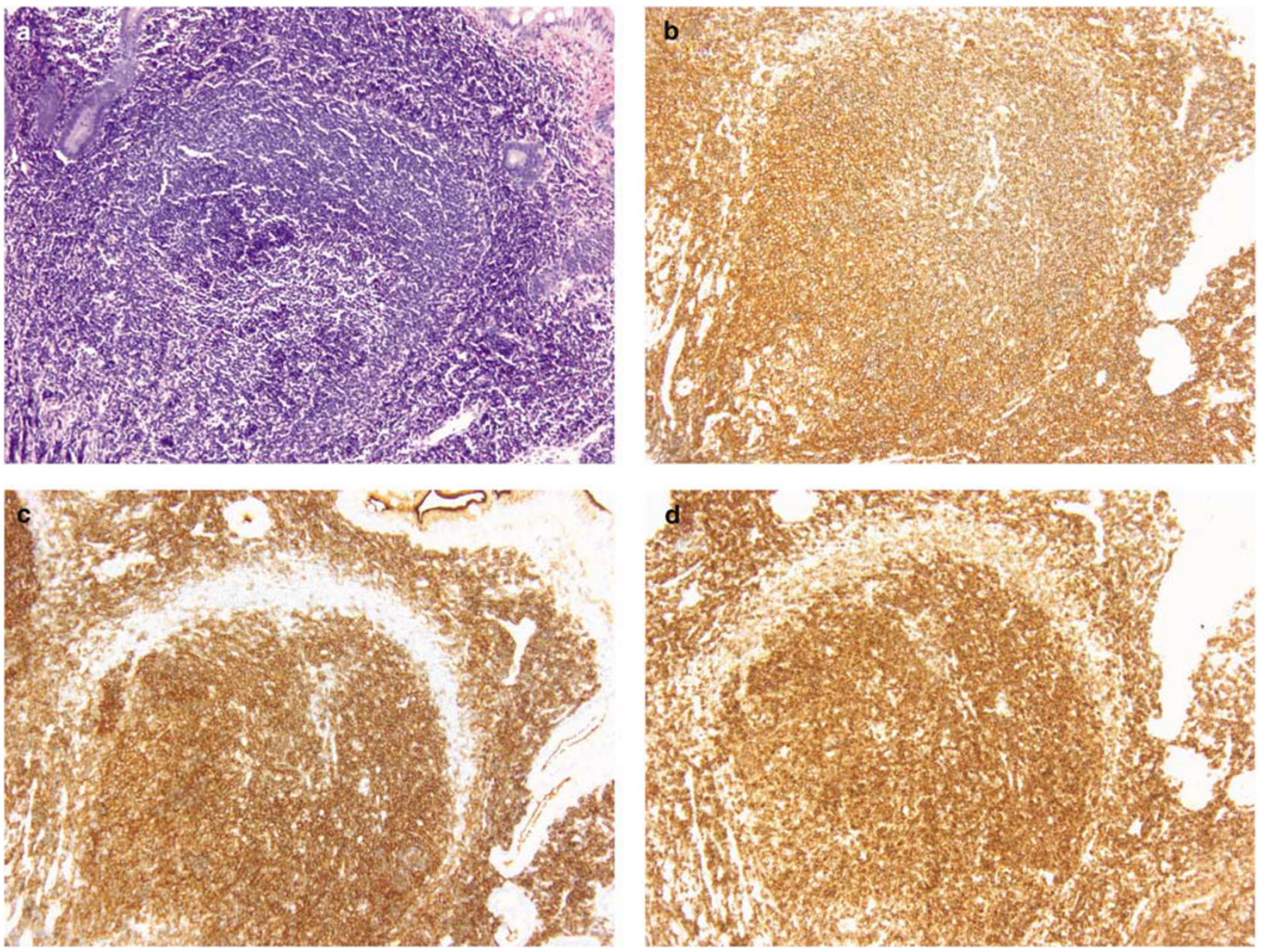

Figure 1 Duodenal follicular lymphoma and immunohistochemical stain (patient no.17). (a) H\&E: A neoplastic follicle is composed of uniform intermediate small-cleaved cells. (b) Tumor cells are positive for CD20 in all cases (c) and for CD10 (d) and bcl-2. 


\section{Results}

\section{Patient Summary and CD21 Expression}

Clinical features (age, gender, clinical stage) and the results of immunohistochemical study are shown in Table 1. The 17 patients (8 males and 9 females) ranged in age from 49 to 75 years with a median age of 61 years. According to the International Workshop (Lugano) Classification, seven cases were clinical stage I, eight cases were stage II and two cases were stage IV. ${ }^{14}$ Histological grade were 1-2 of all cases. All patient samples expressed CD20, CD10, bcl-2 and bcl-6, and were negative for CD5, MUM1 and cyclin D1 by immunohistochemical study (Figure 1). In all cases, the Ki-67 labeling index was $<10 \%$. The presence of a $\mathrm{t}(14 ; 18)(\mathrm{q} 32 ; \mathrm{q} 21) / I G H-B C L 2$ was sought by FISH depending on the material available. The translocation of $18 \mathrm{q} 21$ was detected in 13 of $15(86.7 \%)$ cases (Figure 2 shows the split signal of patient no. 7 sample). We could not detected translocations at two patients' materials.
A typical pattern of follicular dendritic cells expressing CD21 and CD23 in nodal follicular lymphoma is shown in Figure 3 and clearly indicates neoplastic follicles. Nodal follicular lymphoma interacts with follicular dendritic cells, which sometimes provides a diagnostic clue. ${ }^{15}$ On the contrary, out of 17 samples of duodenal follicular lymphomas, 15 showed a very similar pattern of follicular dendritic cells: they were rather densely arranged at the periphery of the neoplastic follicle area but few follicular dendritic cells were detected at the center of the neoplastic follicle area.

In most nodal follicular lymphomas, follicular dendritic cell networks occupied more than twothirds of the neoplastic follicle areas. On the contrary, follicular dendritic cell networks occupied $<10 \%$ of the neoplastic follicle areas in duodenal follicular lymphomas, and were distributed in the periphery of the neoplastic follicles. Accordingly, the nodal pattern was identified as neoplastic follicles coextensive with large follicular dendritic cell networks, whereas the duodenal pattern was
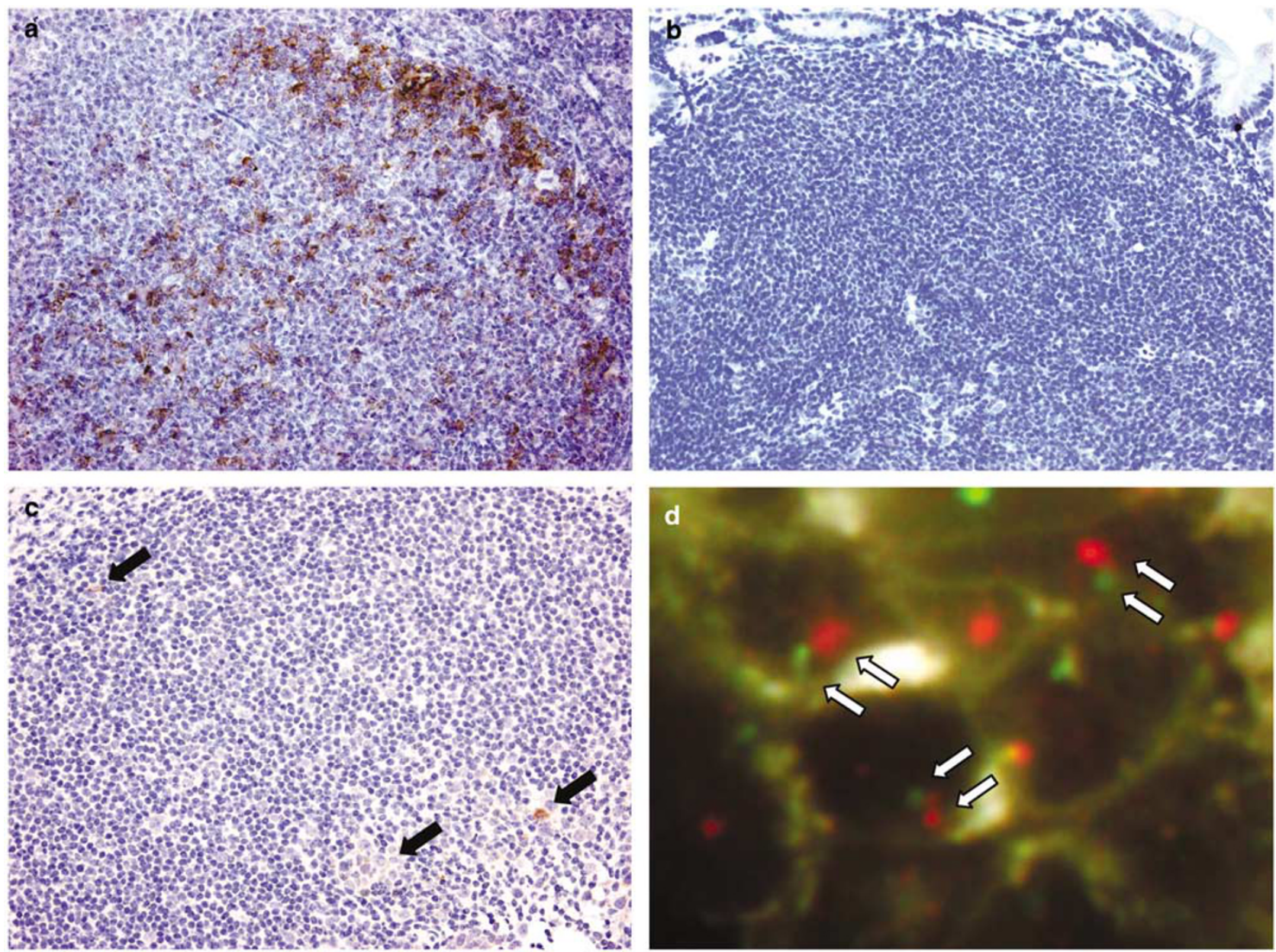

Figure 2 Expression of AID and FISH. (a) AID expression in nodal follicular lymphoma, grade 1. More than 20\% of neoplastic cells are positive. (b) AID expression in duodenal follicular lymphoma (patient no. 8). Almost all neoplastic cells are negative. (c) AID expression in patient no. 2. Some positive cells are shown (arrows). (d) BCL2 split signal of patient no. 7 (arrows: The FISH DNA probes are a mixture of a Texas Red-labeled DNA probe (bcl-2-upstream) and a fluorescein-labeled DNA probe (bcl-2-downstream). Split signals of red- and green-labeled probe are seen in the lymphoma cells, indicating breaking apart of the bcl-2 gene. 

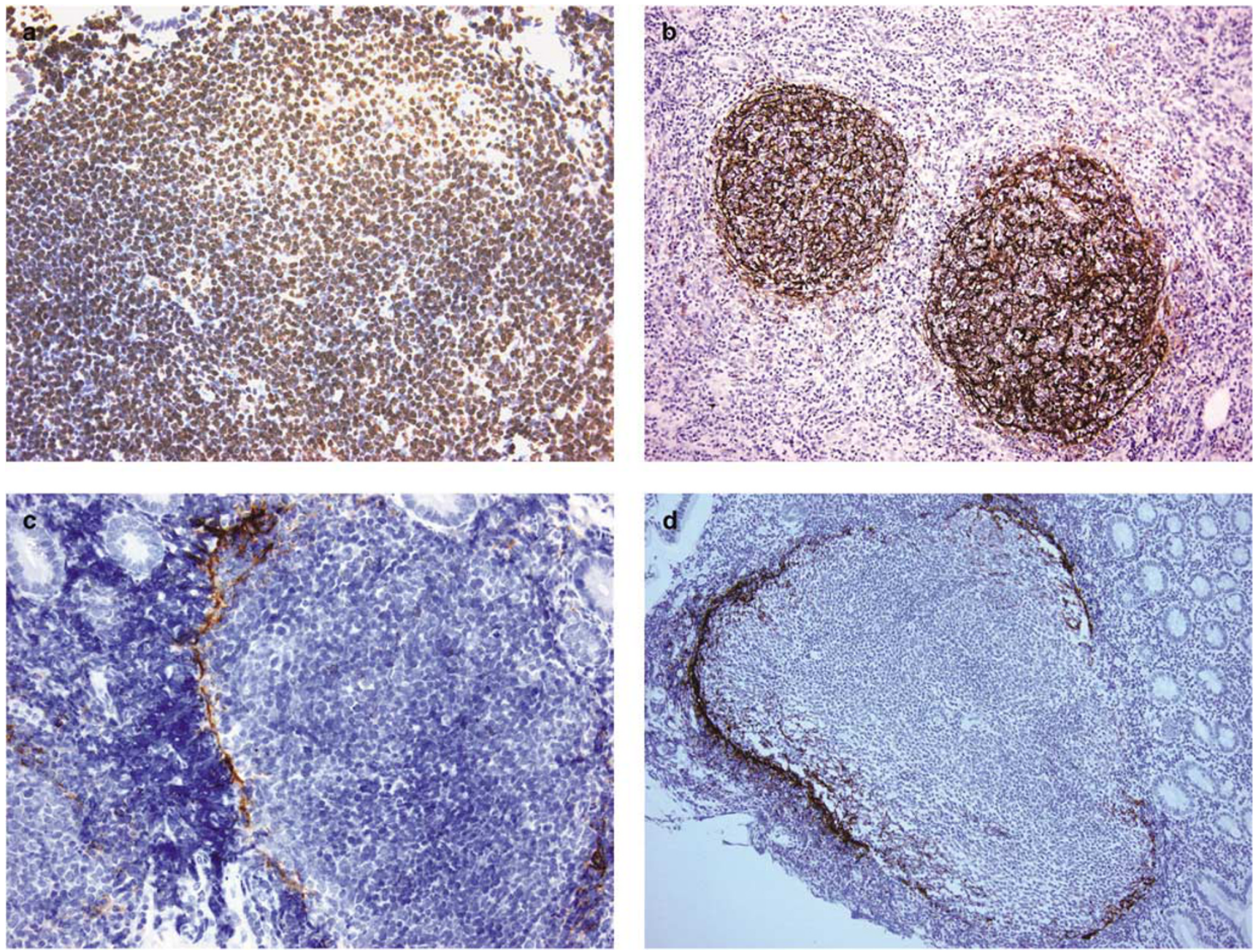

Figure 3 Expression of bcl-6, CD21 and CD23. (a) Tumor cells are positive for bcl-6 in all cases (shows patient no. 8). (b) CD21 expression in nodal follicular lymphoma, grade 1. Follicular dendritic cells are densely found in neoplastic follicles. (c) CD23 expression in duodenal follicular lymphoma (patient no. 17). Follicular dendritic cells are arranged at the periphery of the neoplastic follicle. (d) CD21 expression in other case of duodenal follicular lymphoma. Similar to CD23 expression.

identified as neoplastic follicles with disrupted, peripheral follicular dendritic cell networks.

\section{AID Expression}

In the duodenal follicular lymphomas, one patient sample (no. 9) expressed AID but other samples (16 samples) were almost completely negative for it (Figure 2). By contrast, out of 19 nodal follicular lymphomas, which histological grades were 1-2 in all cases, AID was clearly detected in 16 (Figure 2, data not shown). The difference in AID expression between nodal follicular lymphoma and duodenal follicular lymphoma was significant $(P<0.001)$.

\section{Relationship among Follicular Dendritic Cells, AID, VH and Ongoing Mutation}

The $V H$ gene usage and analysis of somatic hypermutation are shown in Table 2 . We sequenced 17 cases of duodenal follicular lymphoma. The $V H$ gene usage included $9(53 \%)$ samples of $V H 3,5$
(29\%) samples of $\mathrm{VH} 4$ and $3(18 \%)$ samples of $\mathrm{VH} 5$. The distribution of mutations in CDR2 and FR3 are also shown in Table 2. Regardless of AID expression, all samples displayed somatic hypermutation; the mutation frequency was $0.7-15.6 \%$, with an average of $9.1 \%$. In VH5 usage cases, there tended to be a low mutation frequency $(0.7-8.8 \%$, average $3.8 \%)$.

In Table 3, most samples showed ongoing mutations, yielding an average of 19.6-fold more mutations than the expected number of additional mutations because of PCR error. Two AID-negative samples (no. 8 and no. 12) did not have any partially shared or unique mutations. Table 4 shows the nucleotide sequence of the $V H$ gene of patient nos. 12 and 7. In no. 7, there were four partially shared mutation and five unique mutations.

\section{Discussion}

Follicular lymphoma is one of the most frequent indolent lymphomas, and most of them are of nodal 
Table 2 AID expression and immunoglobulin gene analysis

\begin{tabular}{|c|c|c|c|c|c|c|c|c|c|c|}
\hline \multirow[t]{2}{*}{ Patient no. } & \multirow[t]{2}{*}{ AID expression ${ }^{\mathrm{a}}$} & \multirow[t]{2}{*}{ VH usage } & \multirow{2}{*}{$\begin{array}{c}\text { Number of } \\
\text { bases analyzed }\end{array}$} & \multicolumn{2}{|c|}{ CDR2 } & \multicolumn{2}{|c|}{ FR3 } & \multicolumn{2}{|c|}{ Total } & \multirow[t]{2}{*}{ Mutation rate $(\%)^{\mathrm{k}}$} \\
\hline & & & & $R$ & $S$ & $R$ & $S$ & $R$ & $S$ & \\
\hline 1 & - & VH3-73 & 153 & 6 & 1 & 7 & 2 & 15 & 3 & 11.8 \\
\hline 2 & - & VH3-48 & 147 & 3 & 1 & 1 & 3 & 4 & 4 & 5.4 \\
\hline 3 & - & VH3-72 & 153 & 7 & 0 & 5 & 4 & 12 & 4 & 10.5 \\
\hline 4 & - & VH4-34 & 140 & 5 & 0 & 7 & 2 & 12 & 2 & 10 \\
\hline 5 & - & VH5-a & 147 & 0 & 0 & 1 & 0 & 1 & 0 & 0.7 \\
\hline 6 & - & VH3-73 & $141^{\mathrm{c}}$ & 6 & 0 & 6 & 1 & 12 & 1 & 9.3 \\
\hline 7 & - & VH4-b & 144 & 7 & 0 & 7 & 2 & 14 & 2 & 11.1 \\
\hline 8 & - & VH4-39 & 144 & 4 & 0 & 6 & 4 & 10 & 4 & 9.7 \\
\hline 9 & + & VH3-15 & 153 & 8 & 0 & 2 & 6 & 10 & 6 & 10.5 \\
\hline 10 & - & VH5-51 & 147 & 2 & 0 & 1 & 0 & 3 & 0 & 2 \\
\hline 11 & - & VH5-51 & 147 & 3 & 2 & 5 & 3 & 8 & 5 & 8.8 \\
\hline 12 & - & VH4-61 & 144 & 2 & 1 & 2 & 1 & 4 & 2 & 4.2 \\
\hline 13 & - & VH4-39 & 144 & 6 & 1 & 3 & 3 & 9 & 4 & 9 \\
\hline 14 & - & VH3-73 & 153 & 7 & 2 & 3 & 3 & 10 & 5 & 9.8 \\
\hline 15 & - & VH3-23 & 147 & 12 & 0 & 8 & 3 & 20 & 3 & 15.6 \\
\hline 16 & - & VH3-23 & 147 & 6 & 3 & 5 & 3 & 11 & 6 & 11.6 \\
\hline 17 & - & VH3-23 & 147 & 9 & 2 & 8 & 2 & 17 & 4 & 14.3 \\
\hline
\end{tabular}

CDR, complementary determining region; FR, framework region; R, replacement mutation; S, silent mutation.

${ }^{\mathrm{a}}$ Immunohistochemically positive $>20 \%$ in tumor follicles.

${ }^{\mathrm{b}}$ Dividing the total number of R and $\mathrm{S}$ mutations in CDR2 and FR3 by the number of bases analyzed.

${ }^{\mathrm{C}}$ In patient no. 6 , deletion of nine nucleotides were found.

Table 3 AID expression and ongoing mutation in duodenal follicular lymphoma

\begin{tabular}{|c|c|c|c|c|c|c|c|c|c|}
\hline \multirow[t]{2}{*}{ Patient no. } & \multirow{2}{*}{$\begin{array}{c}A I D \\
\text { expression }\end{array}$} & \multirow{2}{*}{$\begin{array}{l}\text { Number of } \\
\text { clones } \\
\text { analyzed }\end{array}$} & \multirow{2}{*}{$\begin{array}{l}\text { Number of } \\
\text { bases } \\
\text { sequenced }\end{array}$} & \multicolumn{4}{|c|}{ Point mutations } & \multirow{2}{*}{$\begin{array}{c}\text { Number of } \\
\text { mutations expected } \\
\text { by PCR error }\end{array}$} & \multirow{2}{*}{$\begin{array}{l}\text { Ongoing } \\
\text { mutation }\end{array}$} \\
\hline & & & & Total & Shared & $\begin{array}{l}\text { Partially } \\
\text { shared }\end{array}$ & Unique & & \\
\hline 1 & - & 10 & 153 & 23 & 16 & 1 & 6 & 0.31 & 22.6 \\
\hline 2 & - & 10 & 147 & 10 & 7 & 1 & 2 & 0.135 & 22.2 \\
\hline 3 & - & 9 & 153 & 18 & 15 & 2 & 1 & 0.24 & 12.5 \\
\hline 4 & - & 10 & 140 & 18 & 14 & 0 & 4 & 0.22 & 18.2 \\
\hline 5 & - & 10 & 147 & 6 & 1 & 0 & 5 & 0.081 & 61.7 \\
\hline 6 & - & 10 & 141 & 21 & 14 & 4 & 3 & 0.28 & 25 \\
\hline 7 & - & 8 & 144 & 21 & 12 & 4 & 5 & 0.28 & 32.1 \\
\hline 8 & - & 10 & 144 & 15 & 15 & 0 & 0 & 0.2 & 0 \\
\hline 9 & + & 10 & 153 & 18 & 17 & 0 & 1 & 0.24 & 4.2 \\
\hline 10 & - & 8 & 147 & 6 & 3 & 0 & 3 & 0.081 & 37 \\
\hline 11 & - & 7 & 147 & 14 & 13 & 0 & 1 & 0.19 & 5.3 \\
\hline 12 & - & 9 & 144 & 6 & 6 & 0 & 0 & 0.081 & 0 \\
\hline 13 & - & 9 & 144 & 19 & 14 & 0 & 5 & 0.26 & 19.2 \\
\hline 14 & - & 10 & 153 & 19 & 15 & 0 & 4 & 0.26 & 15.4 \\
\hline 15 & - & 10 & 147 & 31 & 23 & 8 & 8 & 0.42 & 38.1 \\
\hline 16 & - & 10 & 147 & 22 & 19 & 0 & 3 & 0.3 & 10 \\
\hline 17 & - & 10 & 147 & 24 & 21 & 1 & 2 & 0.32 & 9.4 \\
\hline
\end{tabular}

origin. But recently, intestinal (especially duodenal) follicular lymphomas have appeared with more frequency, and these are considered variants of follicular lymphoma in the fourth WHO classification. ${ }^{16}$ Interestingly, from our surgical files, only $5.8 \%(17 / 290$ cases $)$ of follicular lymphomas were extranodal up to 2001, whereas $30.8 \%$ (153/497 cases) were extranodal in 2002-2007. This frequency needs to be investigated hereafter, but consultation from other institution to our department has not changed in the past 10 years, hence this frequency indicates that intestinal follicular lymphomas have become popular and the incidence of finding them is increasing. The similarity of duodenal follicular lymphomas to MALT lymphomas has been reported from different points of view: expression of $\alpha 4 \beta 7$, which is a mucosal homing receptor, ${ }^{17} \mathrm{VH}$ gene deviation, ${ }^{6}$ and IgA production suggesting that lymphoma cells derive from mucosal B cells. ${ }^{18}$ 
Table 4 Cloning assay of the VH gene of duodenal follicular lymphoma

CDR2

Patient no. 12

VH4-61*08 TATATCTATTACAGTGGGAGCACCAACTACAACCCCTCCCTCAAGAGT

No. 12

Clone 01

Clone 03

Clone 04

Clone 05

Clone 06

Clone 07

Clone 09

Patient no. 7

VH4-b*02

No. 7

Clone 01
Clone 02

Clone 02
Clone 03

Clone 04

Clone 05

Clone 06

Clone 08

AGTATCTATCATAGTGGGAGCACCTACTACAACCCGTCCCTCAAGAGT - - - - - C--CA-------C----------GT---G-----CT---

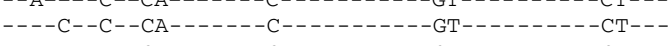
-
FR3

CGAGTCACCATATCAGTAGACACGTCCAAGAACCAGTTCTCCCTGAAGCTGAGCTCTGTGACCGCTGCGGACACGGCCGTGTATTACTGTGCGAGA

С--

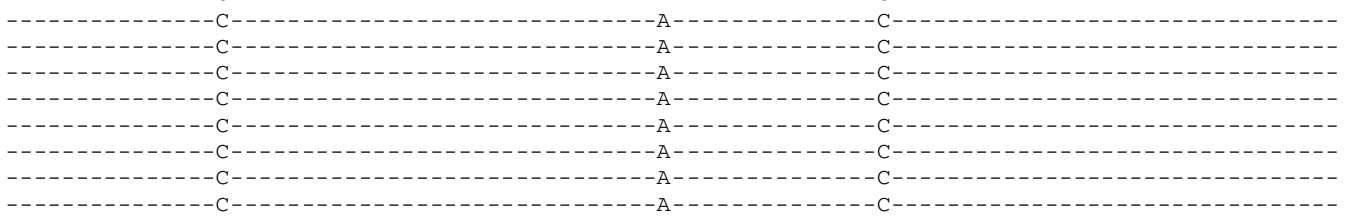
-

CGAGTCACCATATCAGTAGACACGTCCAAGAGCCAATTCTCCCTGAAGCTGAGCTCTGTGACCGCCGCAGACACGGCCGTGTATATTACTGTGCGAGA

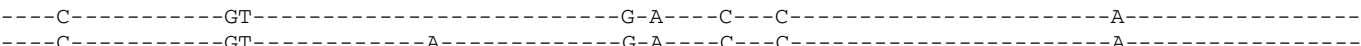
-

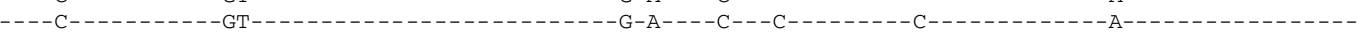
-

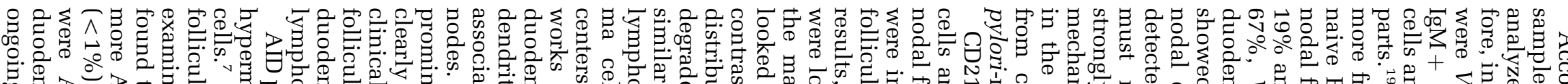

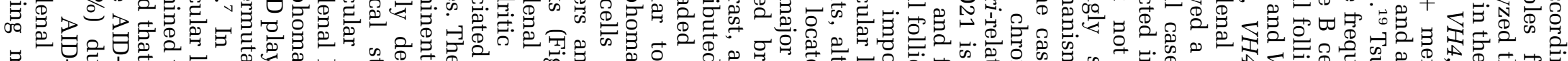

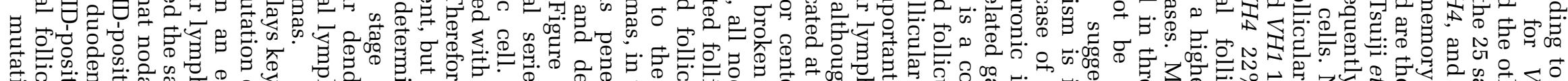

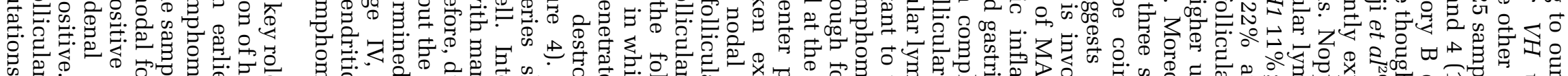
ผ.

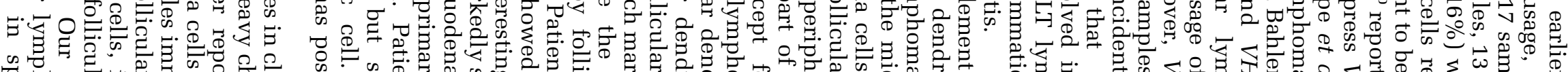
乎. बें

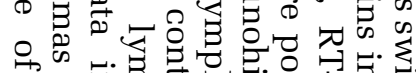

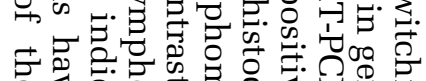

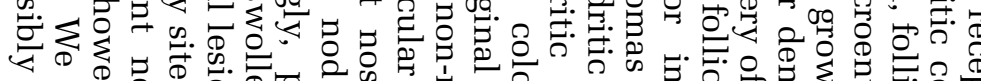

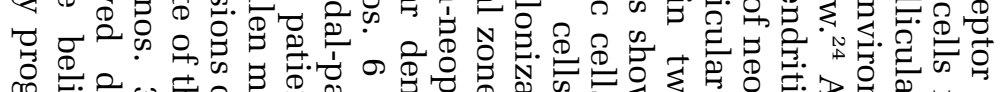

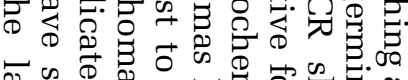

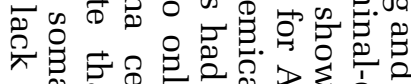

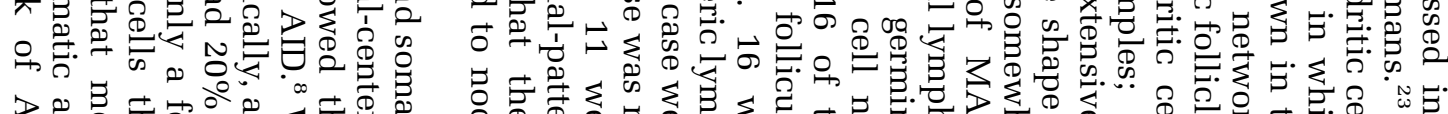

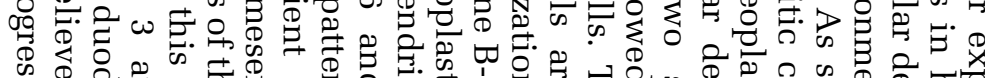
事

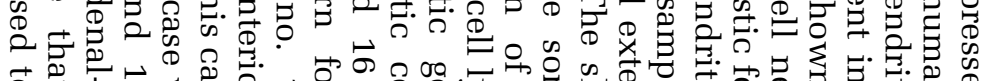

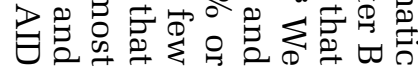

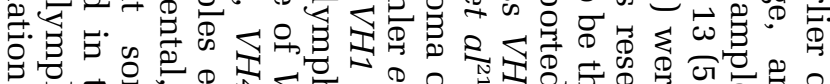

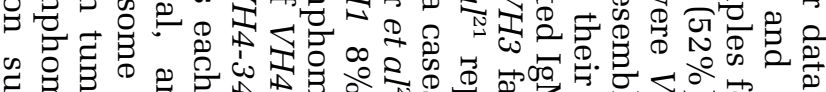

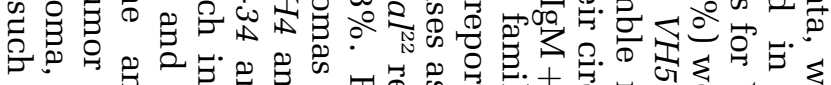

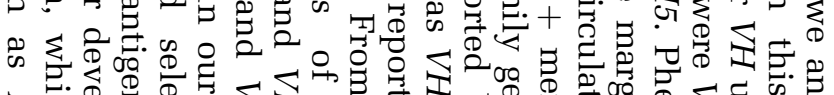

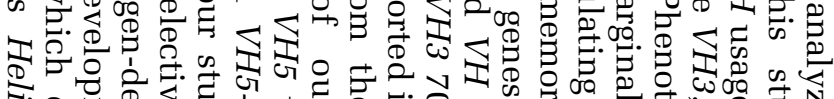

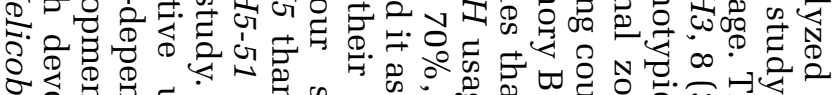

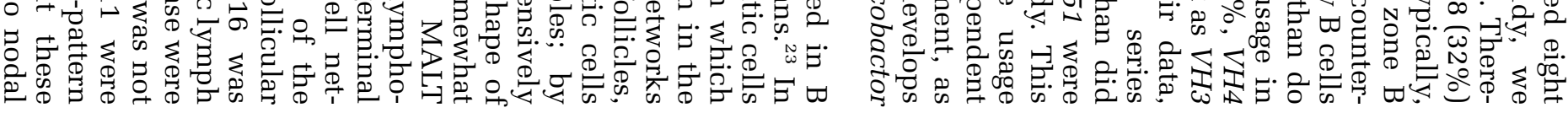



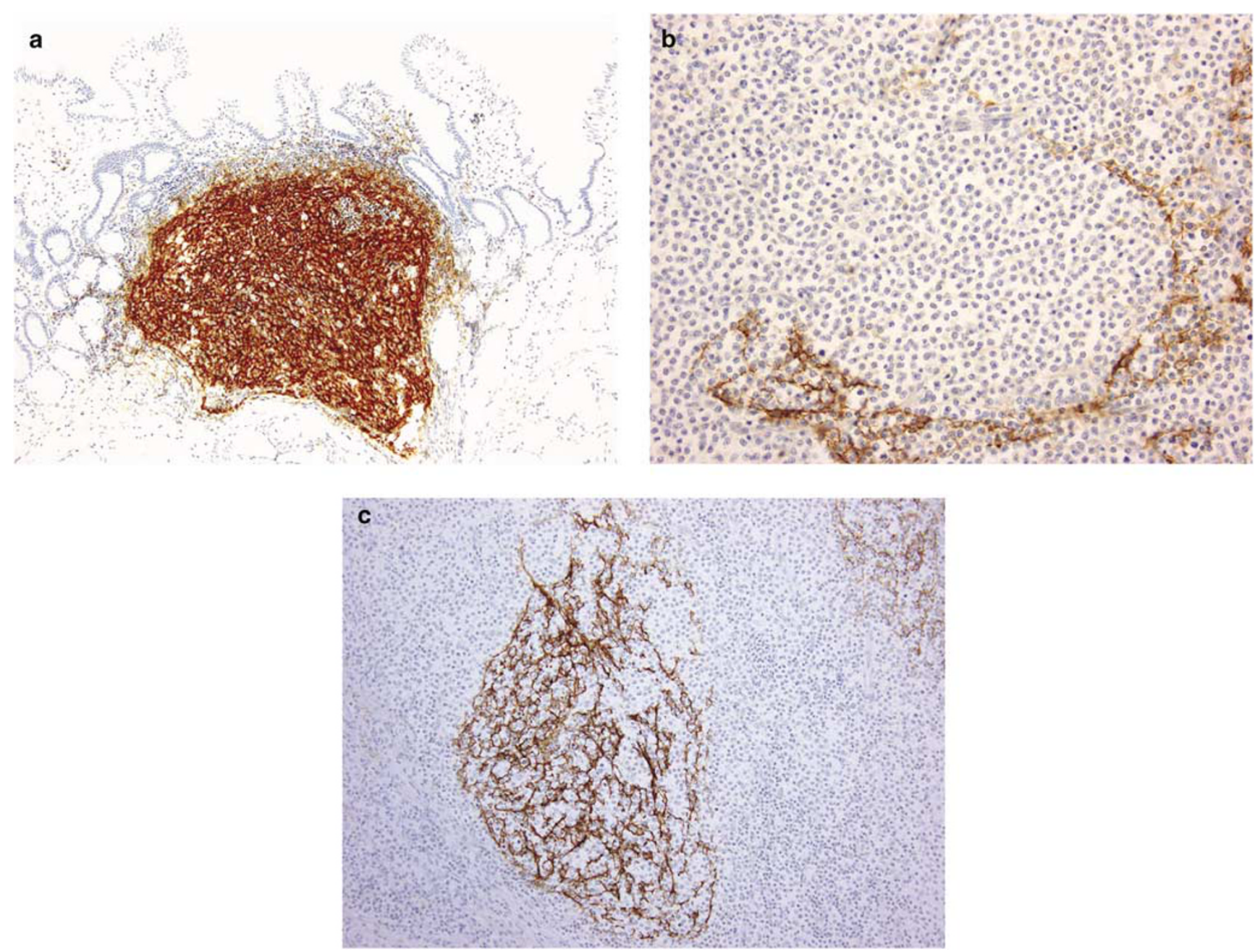

Figure 4 CD21 expression in reactive lymphoid hyperplasia of the duodenum and in MALT lymphoma of the stomach. (a) CD21 expression in reactive lymphoid hyperplasia of the duodenum. Follicular dendritic cell network are present. (b) CD21 expression in MALT lymphoma of the stomach. Follicular dendritic cell network are disrupted (follicular colonization), which is similar to those of duodenal follicular lymphomas. (c) CD21 expression in a non-neoplastic germinal center of a gastric MALT lymphoma. The follicular dendritic cell networks are well preserved.

expression. This sounds contradictory; however, Bombardieri et $a l^{25}$ reported that neoplastic marginal zone-like B cells are AID-negative but have somatic and ongoing mutations. ${ }^{26}$ On the other hand, Smit et al, ${ }^{27}$ Pasqualucci et $a l^{28}$ and Lossos et $a l^{9}$ reported of lack of correlation between AID expression and intraclonal diversity of $\mathrm{VH}$ genes in B-cell non-Hodgkin's lymphomas. And Smit et $a l^{27}$ mentioned that AID expression at follicular lymphomas were $25 \%$, and intraclonal variation was found in the absence of AID, but they did not explained histology, immunophenotype and stage. IgVH mutations were introduced at a tumor stage when AID enzyme was still expressed. However, from our data, almost all of duodenal follicular lymphoma lacks AID in the protein expression level, and histological grade was 1-2. Moreover, all samples expressed bcl-6, which is known to be a target gene for somatic hypermutation in germinalcenter $\mathrm{B}$ cells. ${ }^{29}$ The mechanisms of somatic and ongoing mutation are not clear. Therefore, in duodenal follicular lymphomas, somatic and ongoing mutation may be independent of AID expression.

Conclusions from our data are as follows: duodenal follicular lymphoma cells showed somatic and ongoing mutations similar to nodal ones, as well as CD10 and bcl-2 expressions; however, they did not express AID, and the follicular dendritic cell networks essential for 'follicular pattern' lymphomas were severely disrupted, as in the follicular colonization of MALT lymphomas. We also found out that duodenal follicular lymphoma had $V H$ family deviation marked by the presence of very restricted VH4 and VH5 segments, which strongly indicated that the lymphoma cells are derived from $B$ cells reacting with specific antigens. These findings strongly suggested that duodenal follicular lymphoma is distinct from nodal follicular lymphoma, and has more similarity to MALT chronic 
inflammation-based lymphomas; these similarities will be very important in considering therapeutic countermeasures against this disease.

\section{Acknowledgements}

This work was supported in part by grants from the Japan Society for the Promotion of Science (JSPS no. 19590348). We thank Ms H Nakamura, Ms M Okabe and Ms M Tokunaka for their technical assistance.

\section{Conflict of interest}

The authors declare no conflict of interest.

\section{Authorship statement}

Takata K, Sato Y, Nakamura N and Yoshino T designed and performed the research. Takata K, Okada $\mathrm{H}$ and Tari $\mathrm{A}$ prepared specimens and clinical data. Takata K, Kikuti YY, Ichimura K, Tanaka T, Morito T, Tamura M, Oka T and Kondo E analyzed the data. Takata $\mathrm{K}$ wrote the paper.

\section{References}

1 Yoshino T, Miyake K, Ichimura K, et al. Increased incidence of follicular lymphoma in the duodenum. Am J Surg Pathol 2000;24:688-693.

2 Shia J, Teruya-Feldstein J, Pan D, et al. Primary follicular lymphoma of the gastrointestinal tract. Am J Surg Pathol 2002;26:216-224.

3 Kosmas C, Stamatopoulos K, Papadaki T, et al. Somatic hypermutation of immunoglobulin variable region genes: focus on follicular lymphoma and multiple myeloma. Immunol Rev 1998;162:281-292.

4 Sato Y, Ichimura K, Tanaka T, et al. Duodenal follicular lymphomas share common characteristics with mucosa-associated lymphoid tissue lymphomas. J Clin Pathol 2008;61:377-381.

5 Mannami T, Yoshino T, Oshima K, et al. Clinical, histopathological, and immunogenetic analysis of ocular adnexal lymphoproliferative disorders: characterization of malt lymphoma and reactive lymphoid hyperplasia. Mod Pathol 2001;14:641-649.

6 Sato Y, Nakamura N, Nakamura S, et al. Deviated VH4 immunoglobulin gene usage is found among thyroid mucosa-associated lymphoid tissue lymphomas, similar to the usage at other sites, but is not found in thyroid diffuse large B-cell lymphomas. Mod Pathol 2006;19:1578-1584.

7 Muramatsu M, Kinoshita K, Fagarasan S, et al. Class switch recombination and hypermutation require activation-induced cytidine deaminase (AID), a potential RNA editing enzyme. Cell 2000;102:553-563.

8 Hardianti MS, Tatsumi E, Syampurnawati M, et al. Activation-induced cytidine deaminase expression in follicular lymphoma: association between AID expression and ongoing mutation in FL. Leukemia 2004;18:826-831.

9 Lossos IS, Levy R, Alizadeh AA. AID is expressed in germinal center B-cell-like and activated B-cell-like diffuse large-cell lymphomas and is not correlated with intraclonal heterogeneity. Leukemia 2004;18: 1775-1779.

10 Joseph DK, Dan J, Marwan AY, et al. Bone marrow involvement in patients with nodular lymphocyte predominant Hodgkin lymphoma. Am J Surg Pathol 2004;28:489-495.

11 Nakamura N, Kuze T, Hashimoto Y, et al. Analysis of the immunoglobulin heavy chain gene variable region of CD5-positive and -negative diffuse large B cell lymphoma. Leukemia 2001;15:452-457.

12 Nakamura N, Hashimoto Y, Kuze T, et al. Analysis of the immunoglobulin heavy chain gene variable region of CD5-positive diffuse large B cell lymphoma. Lab Invest 1999;79:925-933.

13 Takada S, Yoshino T, Taniwaki M, et al. Involvement of the chromosomal traslocation $\mathrm{t}(11 ; 18)$ in some mucosa-associated lymphoid tissue lymphomas and diffuse large B cell lymphomas of the ocular Adnexa Evidence from multiplex reverse transcriptase-polymerase chain reaction and fluorescence in situ hybridization on using formalin-fixed, paraffin-embedded specimens. Mod Pathol 2003;16:445-452.

14 Rohatiner A, d'Amore F, Coiffer B, et al. Report on a workshop convened to discuss the pathological and staging classifications of gastrointestinal tract lymphoma. Ann Oncol 1994;5:397-400.

15 Bagdi E, Krenacs L, Krenacs T, et al. Follicular dendritic cells in reactive and neoplastic lymphoid tissues: a reevaluation of staining patterns of CD21, CD23, and CD35 antibodies in paraffin sections after wet heat-induced epitope retrieval. Appl Immunohistochem Mol Morphol 2001;9:117-124.

16 Sweldlow SH, Campo E, Harris NL, et al., editor WHO Classifications of Tumours of Haematopoietic and Lymphoid Tissues, 4th edn, IARC Lyon, 2008; 220-226p.

17 Liu YX, Yoshino T, Ohara N, et al. Loss of expression of alpha4beta7 integrin and L-selectin is associated with high-grade progression of low-grade MALT lymphoma. Mod Pathol 2001;14:798-805.

18 Bende RJ, Smit LA, Bossenbroek JG, et al. Primary follicular lymphoma of the small intestine: alpha4beta7 expression and immunoglobulin configuration suggest an origin from local antigen-experienced B cells. Am J Pathol 2003;162:105-113.

19 Weller S, Braun MC, Tan BK, et al. Human blood IgM 'memory' B cells are circulating splenic marginal zone B cells harboring a pre-diversified immunoglobulin repertoire. Blood 2004;104:3647-3654.

20 Tsuiji M, Yurasov S, Velinzon K, et al. A checkpoint for autoreactivity in human IgM+ memory B cell development. J Exp Med 2006;203:393-400.

21 Noppe SM, Heirman C, Bakkus MHC, et al. The genetic variability of the $\mathrm{VH}$ genes in follicular lymphoma: the impact of the hypermutation mechanism. Br J Haematol 1999;107:625-640.

22 David WB, Michael JC, Sarah $\mathrm{H}$, et al. IgVH gene expression among human follicular lymphomas. Blood 1991;78:1561-1568.

23 Rosendaal R, Carroll MC. Complement receptors CD21 and CD35 in humoral immunity. Immunol Rev 2007;219:157-166.

24 Kagami Y, Jung J, Choi YS, et al. Establishment of a follicular lymphoma cell line (FLK-1) dependent on follicular dendritic cell-like cell line HK. Leukemia 2001;15:148-156. 
25 Bombardieri M, Barone F, Humby F, et al. Activationinduced cytidine deaminase expression in follicular dendritic cell networks and interfollicular large B cells supports functionality of ectopic lymphoid neogenesis in autoimmune sialoadenitis and MALT lymphoma in Sjogren's syndrome. J Immunol 2007;179:4929-4938.

26 Behler DW, Miklos JA, Swerdlow SH. Ongoing Ig gene hypermutation in salivary gland mucosa-associated lymphoid tissue-type lymphomas. Blood 1997;89: 3335-3344.
27 Smit LA, Bende RJ, Aten J, et al. Expression of activation-induced cytidine deaminase is confined to B-cell Non-Hodgkin's lymphomas of germinal-center phenotype. Cancer Res 2003;15:3894-3898.

28 Pasqualucci L, Guglielmino R, Houldsworth J, et al. Expression of the AID protein in normal and neoplastic B cells. Blood 2004;104:3318-3325.

29 Klein UIF, Dalla-Favera R. Germinal centers: role in B-cell physiology and malignancy. Nat Rev Immunol 2008;8:22-33. 